\title{
Preparation of Activated Carbon for Military Camouflage Coating
}

\section{Kittiphop Promdee}

Department of Environmental Science, Chulachomklao Royal Military Academy, Nakhon Nayok, 26001, Thailand

Correspondence Author: Kittiphop Promdee, Department of Environmental Science, Chulachomklao Royal Military Academy, Nakhon Nayok, 26001, Thailand

Received date: 23 October 2018, Accepted date: 15 November 2018, Online date: 25 December 2018

Copyright: (c) 2018 Kittiphop Promdee et al. This is an open-access article distributed under the terms of the Creative Commons Attribution License, which permits unrestricted use, distribution, and reproduction in any medium, provided the original author and source are credited.

\begin{abstract}
This project investigates the potential use of activated carbon in the coating processes of military camouflage. The carbon was produced through carbonization techniques via a rotary kiln reactor, and applied to military camouflage using a thermal coating method. Additives (plasticizer, coupling agent, etc.) were co-thermal coated with binder on the military camouflage. The coating process was assessed, together with the composite materials left on the military camouflage after one or two coating steps. The efficacy of the process in consolidating and protecting the military camouflage was investigated using scanning electron microscopy (SEM) and X-ray fluorescence (XRF).
\end{abstract}

Key words: Military camouflage, Activated carbon, Coating materials, SEM, XRF

\section{INTRODUCTION}

Activated carbon can be prepared by carbonizing and activating organic substances. The raw materials, such as, coconut shells, peat, coal, and petroleum coke may be carbonized and activated at high temperatures [1]. Activated carbon usually increases the cost of the treatment process [2]. Its economical drawback has stimulated the interest to utilize cheaper raw materials for the production of activated carbon [3]. Consequently, a wide variety of agricultural by-products and wastes have been investigated as cellulosic precursors for the production of activated carbon in addition to hard wood and bituminous coal. These precursors include: coconut shell and wood. Coal is also readily available and a reasonably cheap raw material. The activated carbon is obtained depends on the type of coal used and its initial processing prior to carbonization and activation [4].

Military camouflage is the use of camouflage by a military force to protect personnel and equipment from observation by enemy forces. In practice, this means applying color and materials to military equipment of all kinds, including vehicles, ships, aircraft, firing positions, and battledress. Military camouflage is part of the art of military deception. The main objective is to apply composite materials including activated carbon, additives agent and binder for military camouflage coating.

Thermal coating is an industrial coating process that consists of a heat source (flame or other) and a coating material in a powder or wire form, which is melted into tiny droplets and sprayed onto surfaces at high velocity[5]. Thermal sprayed coatings are typically applied to inorganic or metal substrates, but can also be applied to some plastic and polymer substrates. This project was co-researched with a textile company, the Thai Textile Printing Public Company Ltd., where some techniques for the coating process and preparation of the aqueous solution mixed with activated carbon and binder was conceived.

\section{Preparation of Thai Military camouflage}

\section{METHODS}

The camouflage pattern is one of the most widely used and effective camouflages in the military. The Royal Thai Army's camouflage pattern has been designed for use in dense vegetation areas and, like other camouflage patterns, it is very crucial to reach a high degree of harmony and unity with the background color (Fig.1.). However, as the seasons and temperature change, the color of the background vegetation will change correspondingly. Thus, while the traditional camouflage coating may achieve good camouflage effect in the short-term, it may increase the chances of target exposure because of the intense activated carbon contrast on camouflage in the long term.
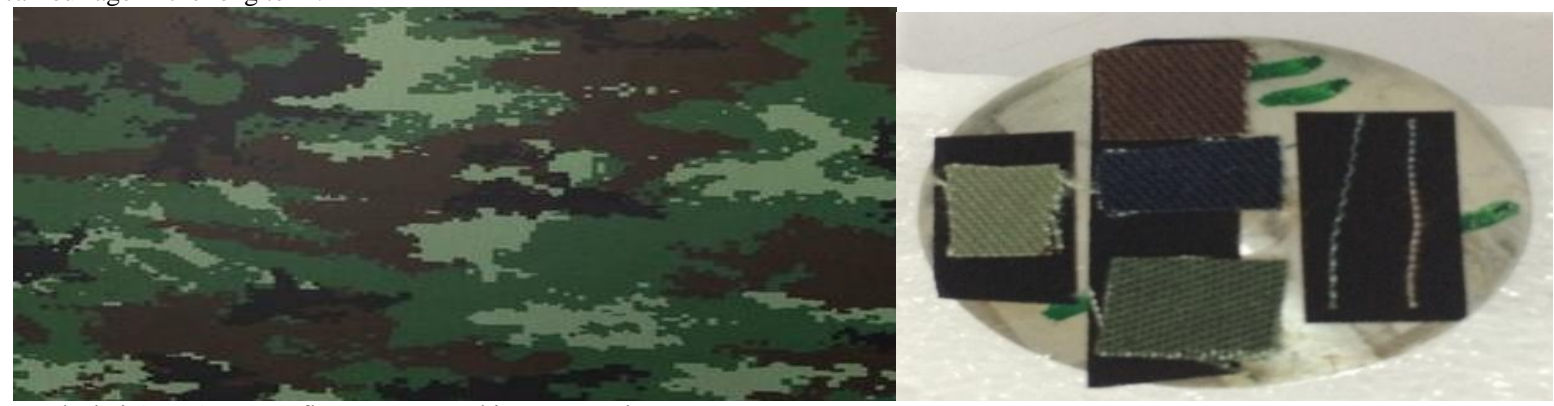

Fig. 1. The Royal Thai Army's camouflage pattern and its separated components.

\section{X-ray fluorescence (XRF)}


$\mathrm{X}$-ray fluorescence analysis is one of the most common non-destructive methods for qualitative and quantitative determination of elemental composition of materials. X-rays cover the part of the electromagnetic spectrum between ultra-violet and gamma radiations. The characteristic wavelengths range from 0.1 to 100 $\AA$ corresponding to energies from 100 to $0.1 \mathrm{keV}$. In the present experiment, we use an X-ray tube. A typical X-ray tube is equipped with a heating filament (usually Tungsten) as a cathode [6]. Due to Joules heating by the electrical current through the filament (glow emission) electrons are emitted and become accelerated in a high electric field towards an anode (target). In research, due to their properties, they are extensively used in elemental and structural analysis. The XRF measurements are carried out on a Philips PW2400 wavelength dispersive spectrometer [7][1]. In addition, some correction factors for determining the influences of other elements were calculated. Measuring conditions were $24 \mathrm{kV}-100 \mathrm{~mA}$ and $60 \mathrm{kV}-40 \mathrm{~mA}$, collimator mask $27 \mathrm{~mm}$ and Rh-X ray tube as excitation source and gas flow detector was used for all elements.

\section{Morphology and Structure analysis}

The morphology and structure of the military camouflage samples were studied via scanning electron microscopy (SEM). The military camouflage samples were dispersed onto carbon tape and imaged using a Zeiss Supra 55 VP field emitter gun scanning electron microscope (FEG-SEM). A Zeiss Supra 55 VP with a Gemini column was used, complemented by additional SEM micrographs of the artery inner wall and calcified area of deplastisized samples using a Leitz-ISI scanning electron microscope[1].

\section{RESULTS AND DISCUSSION}

The combined effect of the rotary kiln process of carbon materials leads to hierarchically porous features [8][9]. The coating processes of military camouflage based on activated carbon was prepared using carbonization techniques via rotary kiln reactor. In this study, SEM was used to analyze the textural components present in activated carbon and their impact on the quality of activated carbon. This result is further confirmed by the SEM images. A transparent mesopores and micropore with a rough surface (Fig. 2a and Fig. 2b) implies that micropores exist in the surface and the interior of activated carbon.

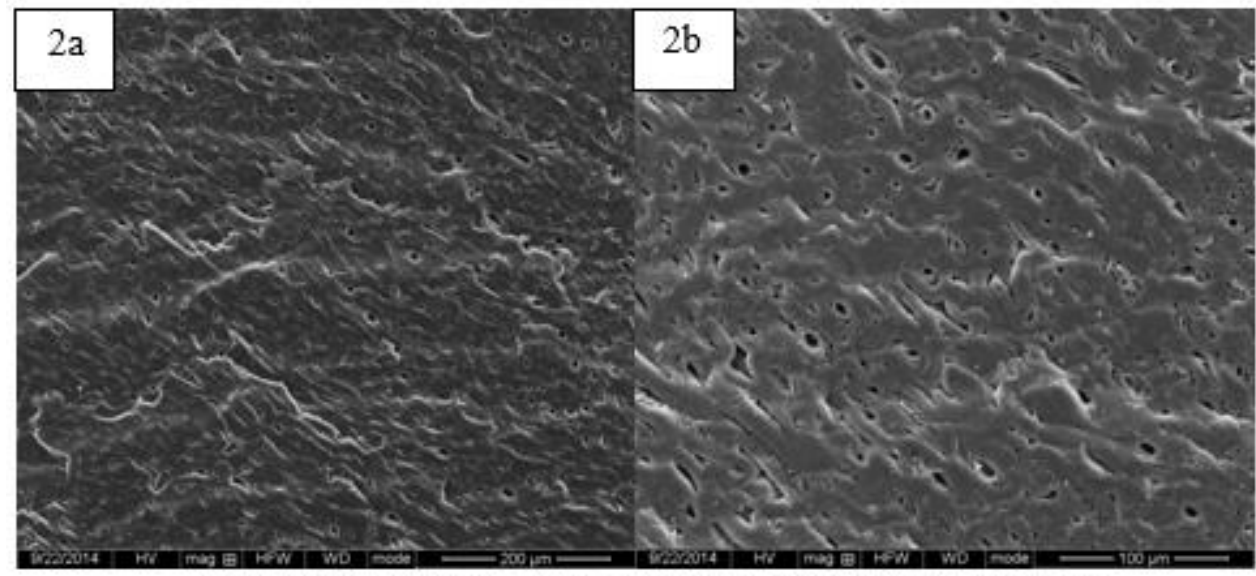

Fig. 2. SEM images of activated carbon; [magnification at $200 \mathrm{x},(2 \mathrm{a})$ and $400 \mathrm{x}(2 \mathrm{~b})$ ].

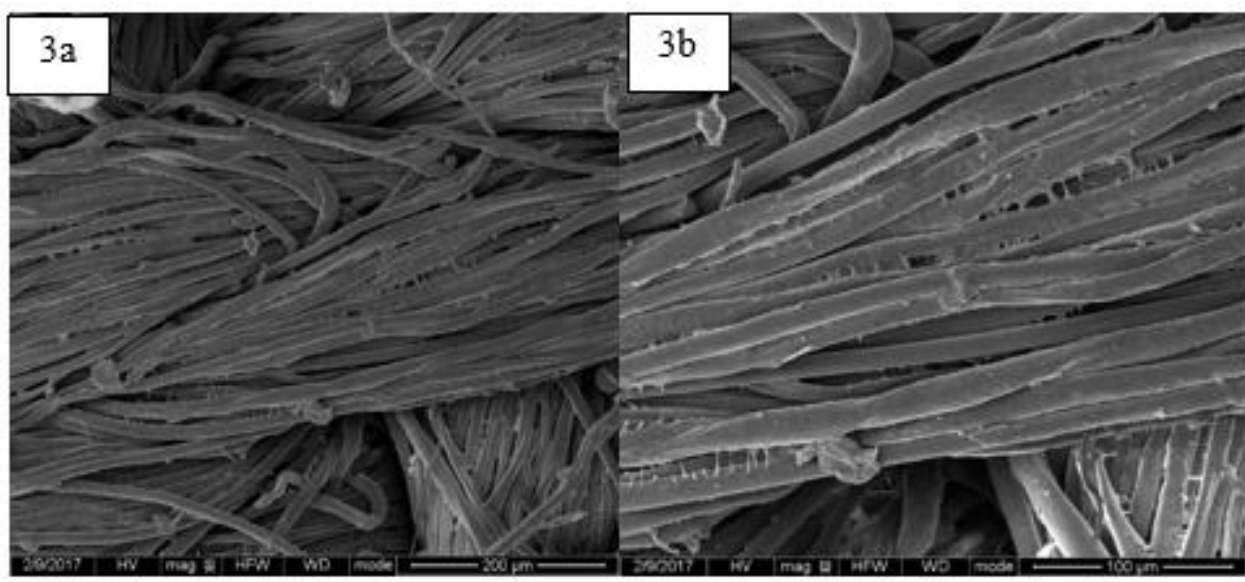

Fig. 3. SEM images of the Royal Thai Army's camouflage:- [magnification at 200x, (3a) and 400x (3b)].

The magnified SEM cross-section image 200x and 400x (Figs. 3a and 3b., respectively) reveals the complex fiber of this military camouflage. Military camouflage surface images demonstrates the surface roughness of the fiber, as arranged inside the military camouflage textile. The SEM image of military camouflage shows that the binder formed is different from the one obtained at its surface. The formation of a uniform, dense layer along the cross section with composite binder could be detected.

The micrograph of the activated carbon further demonstrates the transformation of the shell's matrix as a result of continued heating during the activation. The magnified SEM cross-section image reveals the composite materials between activated carbon and tapioca flour binder, which has a smooth features and also a smooth arrangement characterized as amorphous.

The results show how XRF intensities of activated carbon correspond with different temperatures (Tables.1 and 2). This correspondence is most clearly seen when thermal kiln process is used. It is reasonable the effect of charcoal composition to assume that low and high thermal occurs inside the kiln with time and XRF measurements.

An XRF calibration for the various elements is based on the fundamental parameters procedure with thermal factors[7] 
Citation: Kittiphop Promdee, 2018. Preparation of Activated Carbon for Military Camouflage Coating. Journal of Applied Sciences Research., 14(6): 18-22. DOI: 10.22587/jasr.2018.14.6.4

Table 1: XR-F calibration Measurements of Activated carbon.

\begin{tabular}{|c|c|c|}
\hline \multicolumn{3}{|c|}{ Low temperature operation in $200^{\circ} \mathrm{C}$} \\
\hline Oxide: & wt. \% & (element) ppm \\
\hline $\mathrm{SiO}_{2}$ & 29.4125 & 137482.85 \\
\hline $\mathrm{P}_{2} \mathrm{O}_{5}$ & 10.125 & 44187.53 \\
\hline $\mathrm{Mo}_{2} \mathrm{O}_{3}$ & 1.4371 & 11495.51 \\
\hline $\mathrm{SO}_{3}$ & 0.3475 & 1391.74 \\
\hline $\mathrm{Cl}_{2} \mathrm{O}$ & 5.0476 & 41183.37 \\
\hline $\mathrm{K}_{2} \mathrm{O}$ & 16.0551 & 133281.41 \\
\hline $\mathrm{CaO}$ & 33.8786 & 242126.97 \\
\hline $\mathrm{TiO}_{2}$ & 0.6869 & 4116.87 \\
\hline $\mathrm{V}_{2} \mathrm{O}_{5}$ & 0.0343 & 192.14 \\
\hline $\mathrm{MnO}$ & 0.2853 & 2209.53 \\
\hline $\mathrm{Fe}_{2} \mathrm{O}_{3}$ & 2.0719 & 14491.49 \\
\hline $\mathrm{ZnO}$ & 0.2366 & 1901.01 \\
\hline $\mathrm{SrO}$ & 0.3816 & 3226.77 \\
\hline
\end{tabular}

The process produces activated carbon, which makes the surface area increase due to the porous structure, where this structure can be studied by XRF. When the object hits the structure, activated carbon become crystalline $[10,11]$. The purity concentration of $\mathrm{SiO}_{2}$ in activated carbon was measured by $\mathrm{XRF}$ as shown in Fig 3 and Fig, 4 to be in the range of 20-30 wt.\% at different temperatures with major impurities of $\mathrm{P}_{2} \mathrm{O}_{5}, \mathrm{Cl}_{2} \mathrm{O}, \mathrm{K}_{2} \mathrm{O}$, and CaO. The purity of produced silica seems to be affected by processing condition including heat [12].

Table 2: XR-F calibration Measurements of Activated carbon.

\begin{tabular}{|c|c|c|}
\hline \multicolumn{3}{|c|}{ High temperature operation in $600{ }^{\circ} \mathrm{C}$} \\
\hline Oxide: & wt.\% & (element) ppm \\
\hline $\mathrm{SiO}_{2}$ & 19.6004 & 91618.15 \\
\hline $\mathbf{P}_{2} \mathbf{O}_{5}$ & 5.2407 & 22871.46 \\
\hline $\mathrm{SO}_{3}$ & 1.0956 & 4387.88 \\
\hline $\mathrm{Cl}_{2} \mathrm{O}$ & 2.1794 & 17786.08 \\
\hline PdO & 4.2242 & 36724.77 \\
\hline $\mathbf{K}_{2} \mathbf{O}$ & 7.2079 & 59899.81 \\
\hline $\mathrm{CaO}$ & 54.2367 & 387624.27 \\
\hline BaO & 0.4305 & 3855.77 \\
\hline $\mathrm{TiO}_{2}$ & 1.4215 & 8519.62 \\
\hline MnO & 0.1748 & 1353.76 \\
\hline $\mathrm{Fe}_{2} \mathrm{O}_{3}$ & 3.549 & 24822.77 \\
\hline $\mathrm{ZnO}$ & 0.229 & 1839.95 \\
\hline SrO & 0.4105 & 3471.15 \\
\hline
\end{tabular}

Trend of contents (wt.\%) in molecular compounds of activated carbon at $200^{\circ} \mathrm{C}$ (Fig. 4) and $600^{\circ} \mathrm{C}$ (Fig. 5), respectively, showed the conversion of SiO $\mathrm{P}_{2} \mathrm{O}_{5}, \mathrm{Cl}_{2} \mathrm{O}, \mathrm{K}_{2} \mathrm{O}, \mathrm{MO}_{2} \mathrm{O}_{3}$ decreased slightly, due to increasing temperature. Conversely, $\mathrm{Fe}_{2} \mathrm{O}_{3}, \mathrm{SrO}$, TiO 2 and PdO gave higher contents when temperature was increased. Figure 6, shows the preparation of activated carbon powder, additives agent, and binder for coating process on military camouflage at the Thai Textile Printing Public Company Ltd. by thermal coating process.

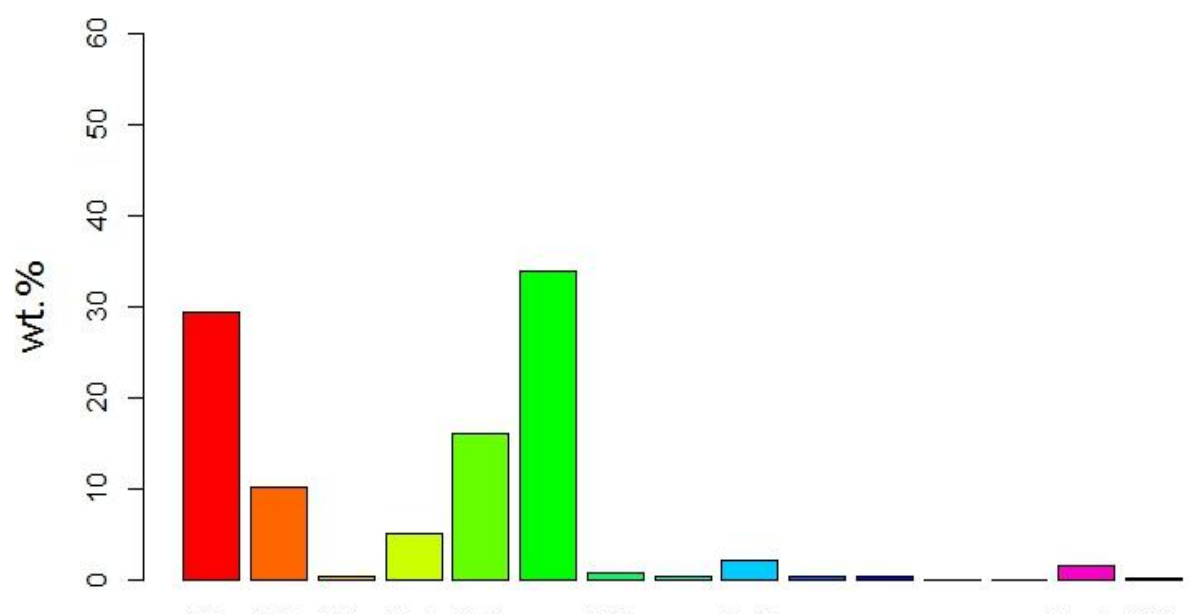

Figure. 4. Activated carbon component at $200^{\circ} \mathrm{C}$. 


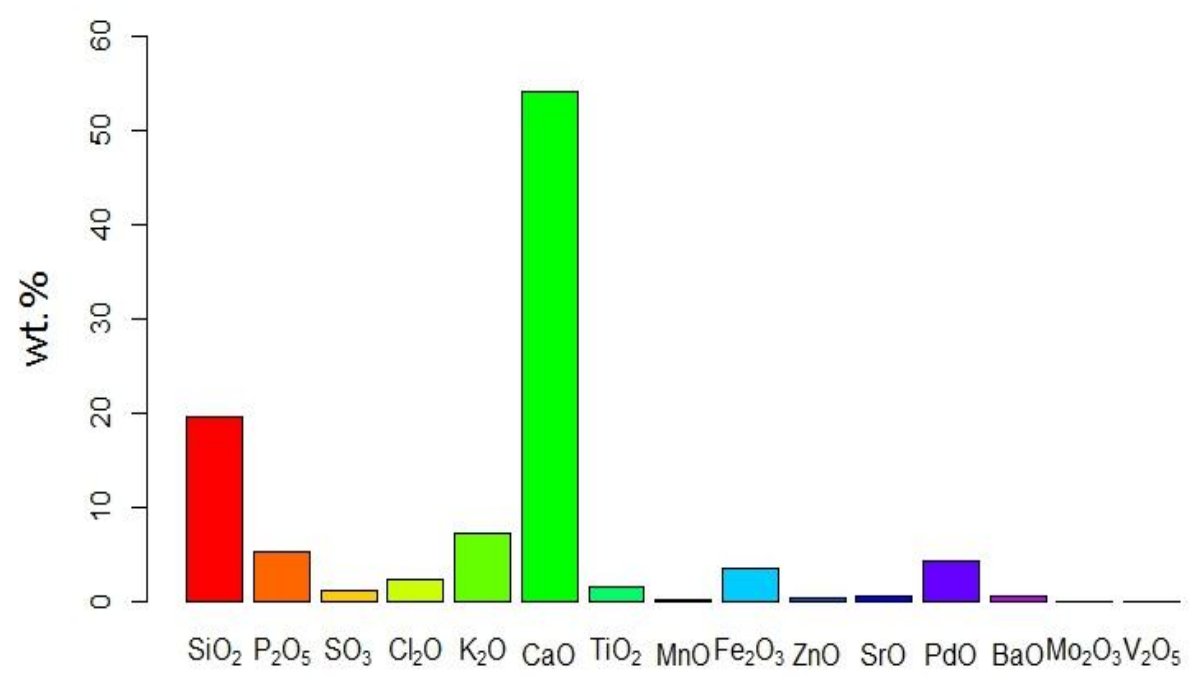

Figure. 5. Activated carbon component at $600^{\circ} \mathrm{C}$.

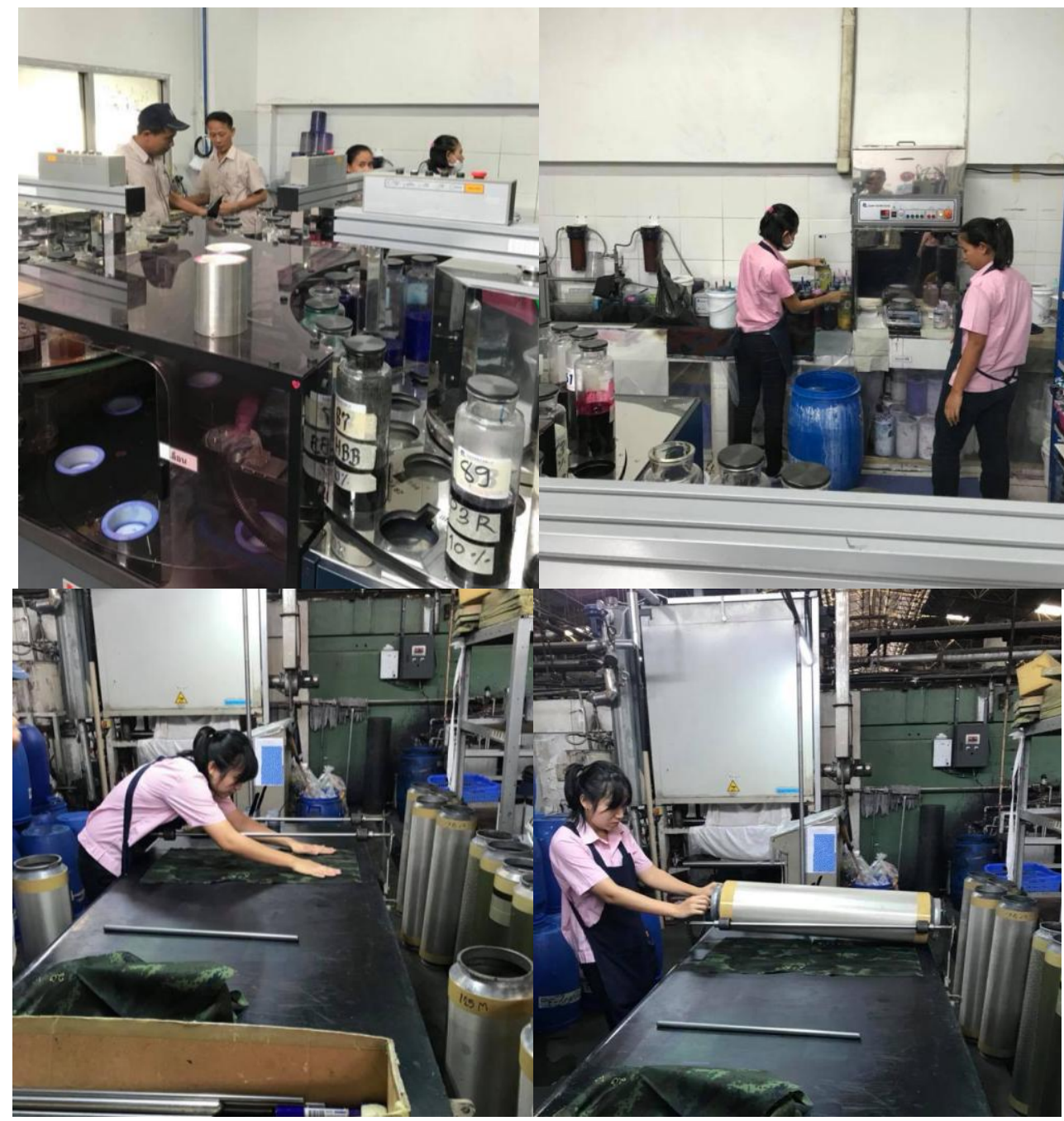

Figure. 6. Coating processes of military camouflage by thermal coating process.

\section{CONCLUSIONS}

The thermal coating process of military camouflage based on activated carbon plasticizer, coupling agent, and binder showed a good result of SEM and XRF. The SEM image of military camouflage shows that the binder formed is different from the one obtained at its surface. The formation of a uniform, dense layer along the cross-section with composite binder could be detected. The magnified SEM cross image 200x and 400x of activated carbon and military camouflage demonstrates the possibility to coat a camouflage texture through the thermal process with plasticizer, coupling agent, and binder. The XRF of activated carbon showed the purity concentration of $\mathrm{SiO}_{2}$ and exists in the range of 20-30 wt.\% with major impurities of $\mathrm{P}_{2} \mathrm{O}_{5}, \mathrm{Cl}_{2} \mathrm{O}, \mathrm{K}_{2} \mathrm{O}$, and $\mathrm{CaO}$. 


\section{REFERENCES}

[1] K. Promdee J. Chanvidhwatanakit, S. Satitkune, C. Boonmee, T. Kawichai, S. Jarernprasert, T. Vitidsant. 2017. Characterization of Carbon Materials and Differences from Activated Carbon Particle (ACP) and Coal Briquettes Product (CBP) Derived from Coconut Shell via Rotary Kiln. Renewable and Sustainable Energy Reviews. $75: 1175-1186$

[2] Xin Yao, Qiang Xie, Chuan Yang, Bo Zhang, Chaoran Wan, Shanshan Cui. 2016. Additivity of pore structural parameters of granular activated carbons derived from different coals and their blends. International Journal of Mining Science and Technology. 26:661-667.

[3] Roberto Volpe, Antonio Messineo, Marcos Millan. 2016. Carbon reactivity in biomass thermal breakdown. Fuel. 183: $139-144$.

[4] Ruofei Chen, Liqing Li, Zheng Liu, Mingming Lu, Chunhao Wang, Hailong Li, Weiwu Ma \& Shaobin Wang. 2017. Preparation and characterization of activated carbons from tobacco stem by chemical activation. Journal of the Air \& Waste Management Association. 67(6): 713-724.

[5] K.V.Sreenivasa RaoK.G.GirishaRPooja ShreeManishKumar. 2017. Effect of Surface Coatings on Thermal performance of steel Substrates. Materials Today Proceeding. 4(9): 10249-10253.

[6] Zivanovic V. 2011. XRF analysis of mineralogical matrix effects and differences between ulverized and fused ferromanganese slag. Chemical Industry \& Chemical Engineering Quarterly. 17(2): 231-237.

[7] Beata Szczepanik, Piotr Słomkiewicz, Magdalena Garnuszek, Kamil Czech, Dariusz Banaś, Aldona Kubala-Kukuś, Ilona Stabrawa. 2016. The effect of chemical modification on the physico-chemical characteristics of halloysite: FTIR, XRF, and XRD studies. Journal of Molecular Structure. 1084 : 16-22.

[8] A. Donatelli, P. Garzone, P. Iovane. 2015. Discharging granular material from a rotary kiln in a slumping regime: Theoretical and experimental studies. Particuology. $23: 56-61$.

[9] J. Bujak. 2016. Thermal treatment of medical waste in a Discharging granular material from a rotary kiln. Journal of Environmental Management. 162 : 139 147.

[10] Jiaxun Liu, Xiumin Jiang, Yuchen Zhang, Hai Zhang, Lei Luo, Xiaoye Wang. 2016. Size segregation behavior of heavy metals in superfine pulverized coal using synchrotron radiation-induced X-ray fluorescence. Fuel. $181: 1081-1088$.

[11] Kang Sun, Chang-yu Leng, Jian-chun Jiang, Quan Bu, Guan-feng Lin, Xin-cheng Lu, Guang-zhen Zhu. 2017. Microporous activated carbons from coconut shells produced by self-activation using the pyrolysis gases produced from them, that have an excellent electric double layer performance. New Carbon Materials. 32 (5):451 - 459.

[12] J. Krýsa, M. Baudys, X. Vislocka, M. Neumann-Spallart. Composite photocatalysts based on $\mathrm{TiO}_{2}-$ carbon for air pollutant removal: Aspects of adsorption. Catalysis Today. In press, Corrected proof, Available online, 13 October 2018. 